\title{
HISTÓRIA DO DIREITO, CIÊNCIA E DISCIPLINA
}

\author{
Luiz Carlos de Azevedo \\ Professor Associado do Departamento de Direito Processual da \\ Faculdade de Direito da Universidade de São Paulo \\ Desembargador aposentado do Tribunal de Justiça de São Paulo
}

\begin{abstract}
Resumo:
O autor busca, em sua obra, demonstrar a importância do estudo da História do Direito para a compreensão dos institutos jurídicos atuais, procurando no passado (associado aos momentos político-histórico e cultural) respostas para as mudanças daqueles. Também procura mostrar a importância deste estudo para os vários ramos do Direito, além de fazer breve análise de suas fontes. Traça, ainda, a evolução do curso de História do Direito em Portugal, a criação e desenvolvimento deste no Brasil, bem como a sua presença nos mais variados cursos de Direito em todo o mundo.
\end{abstract}

\begin{abstract}
:
The author aims, at his work, to show the importance of the study on History of Law due the understanding of nowadays juridical institutes, looking at the past (coordinated with political, historical and cultural miment) for answers that explain those. He also intends to show the importance of this study for the various wings of Law, yonder a short analysis of its resources. He defines, yet, the evolution of the Law History of Portugal, the creation and development of this one in Brazil, as well its presence in various studies of Law thoroughout the world.
\end{abstract}

Unitermos: História do Direito; evolução do curso de História do Direito.

Sumário:

1. Introdução.

2. Conceito de História do Direito.

3. A História do Direito e os vários ramos da ciência jurídica. Interdisciplinaridade. Fontes.

4. A História do Direito, disciplina obrigatória integrante dos cursos jurídicos.

5. O ensino da História do Direito no Brasil.

6. O ensino da História do Direito no exterior.

7. A consolidação da História do Direito como disciplina obrigatória do currículo do curso de graduação da Faculdade de Direito da Universidade de São Paulo. 


\section{Conclusão.}

Bibliografia.

\section{Introdução.}

Todo Estado dispõe de ordenamento jurídico próprio, composto de normas nas quais se distinguem determinados valores protegidos pelo Direito. Estes valores, ou bens jurídicos, contam com maior ou menor amparo perante as respectivas normas que os resguardam, conforme a natureza e relevância que estas lhes emprestaram, no momento em que editadas e em face do ambiente social para o qual se destinaram; e como o substrato social se encontra em continuada alteração, também aquelas vão conhecendo periódicas mudanças, de acordo com a época e conveniência de sua manutenção, ou-não.

Assim, conforme as exigências de ordem política, econômica ou cultural, um ato antijurídico, que estava a merecer apenas uma repressão de caráter civil, é colocado pelo legislador sob outro prisma de valores, e a necessidade de se proteger a ordem jurídica provoca, então, uma sanção mais rigorosa para a hipótese; ou ocorre o inverso, e o ato, embora continue sendo reconhecido como ilícito, deixa de sofrer aquela pena, passando a ser coibido ou condicionado a outros meios igualmente válidos para o restabelecimento do direito atingido.

Ora, para que se possa bem compreender todo o envolvimento que este problema comporta, não é possível se ater unicamente ao momento em que o ato acaba de ser praticado e ao dispositivo legal que o regulamenta ou sanciona; é preciso ir mais além, colhendo este e aquele na sua inteira extensão e plenitude, para visualizá-los sob um critério amplo e abrangente; na verdade, se o Direito constitui uma expressão inseparável de qualquer meio social civilizado; e se este Direito não se conserva estático, mas se dinamiza e se transforma na medida em que as condições sociais assim exigem; não há como desvinculá-los da realidade histórica, pois é preciso saber como este Direito foi, até ontem, para entendê-lo, hoje, e melhorá-lo, amanhã. 
Já se disse que a ordem jurídica se assemelha a um imenso relógio, repleto de engrenagens: algumas delas, possuem movimento rápido e visível; outras, mais moroso e apenas perceptível; outras, enfim, trazem movimento tão-lento, que parecem imóveis. Por isso, para medi-las, deve-se considerá-las dentro de um larguíssimo período de tempo. E são justamente estas engrenagens mais lentas que não podem ser desprezadas; ao revés, devem ser levadas em consideração, antes que as outras; ou, por outra, deve-se atentar, de preferência, para aqueles institutos que revelaram possuir maior longevidade e estabilidade, porque foram eles que influenciaram o pensamento jurídico em maior profundidade e dimensão.'

Ora, como buscar a evolução de um determinado Direito sem se valer do concurso da História e sem cuidar dos fundamentos sociais, políticos, econômicos e culturais que dirigiram a conduta do conglomerado humano que o adotou e utilizou?

Daí a importância inestimável da História do Direito: fornecer ao Direito atual a compreensão dessa retrospectiva, esclarecendo dúvidas, afastando imprecisões, levantando, passo a passo, a verdadeira estrutura do ordenamento, seus institutos mais sólidos e perenes, suas bases de fundo e suas características formais, até alcançar a razão de ser de seu significado e conteúdo.

\section{Conceito de História do Direito.}

Mas a História do Direito não se reduz a um inventário, nem se limita a erguer e revolver os antecedentes históricos das instituições ora vigentes; explicase, não pela volta às antigüidades jurídicas, mas pelo fato de constituir o "único caminho para a compreensão da essência do Direito" na sua atual conjuntura. ${ }^{2}$

Na condição de ciência que é, descreve e revela; pesquisa e esclarece; coordena e explicita a vida jurídica de um povo em seus mais variados aspectos, detendo-se nas fontes, nos costumes, na legislação que o rege, em todas as manifestações, enfim, que possibilitem o aperfeiçoamento dessa compreensão como um todo, resultante do conhecimento dos fatos ocorridos e das impressões maiores ou menores que estes deixaram.

1. Bruno Paradisi, Questioni Fondamentali per una Moderna Storiografia del Diritto, in "Apologia della storia giuridica", Bologna, 1973, Il Mulino, pp. 488-489.

2. José Manuel Pérez-Prendes Y Muñoz De Arracó, Curso de Historia del Derecho Español, Madri, Ed. Darro, 1978, p. 17. 
É tanto uma ciência histórica, quanto jurídica; em face desta dualidade, sua área de atuação não se restringe a limites rígidos ou previamente direcionados; já que não se conforma com a mera descrição dos fenômenos jurídicos, deve compreendê-los e explicá-los desde o momento em que sucederam, como na sequiência temporal na qual persistiram sobrevivendo ou deixando de existir.

Não é um trabalho fácil: para bem entender o significado e alcance de um determinado ordenamento de natureza jurídica, o pesquisador desdobra o seu estudo por etapas, dirigindo-se, primeiramente, ao conteúdo das normas e instituições; partirá, depois, para as condições sociais que levaram ao estabelecimento daquelas e destas; competirá perscrutar o problema da efetividade do ordenamento no meio que lhe corresponde, certificando-se de que forma e em que medida tais e quais institutos ainda se encontram válidos, por que desapareceram, ou, ainda, por que não dispõem nem exercem mais a influência que antes gozavam. ${ }^{3}$

Um esforço de tal porte não interessa apenas sob o ponto de vista histórico, circunscrito ao retrospecto dos fatos e atos vividos e legados aos pósteros; mas traduz utilidade, também, ao jurista de hoje, prático, técnico, dogmático, pois não é possível desvincular o Direito atual das causas que determinaram a sua juridicidade.

Há verdades fundamentais a serem consideradas: por mais que se pretenda afogar o passado, o fundo tradicional sempre emerge, principalmente quando se cuida de uma ciência como o Direito, a qual, por índole, é mais conservadora do que as outras; e por mais que se removam ou substituam as instituições, nunca se desprezam, por inteiro, aquelas que consolidaram a estrutura básica da sociedade, as quais perduram no tempo e no espaço à conta de inarredável condicionalismo histórico.

Ademais, se alguém aspira a empenhar-se com afinco ao estudo do Direito, empregando-o e utilizando-o para o exercício de sua atividade profissional, não pode reduzir-se à leitura sistemática dos textos legais vigentes, aplicando-os mecanicamente na medida em que se possam ajustar aos casos concretos; a tarefa é sobremaneira ingente: compreensão e explicação; sugestões e idéias; experiência e interpretação, são qualidades que se integram a este trabalho; e no qual se insere, por

3. Helmut Coing, Las Tareas del Historiador del Derecho, trad. de Antônio Merchán, Sevilha, Universidad de Sevilla, 1977. 
sua vez, a História do Direito, pois ela ensina que o Direito não surgiu espontaneamente ex nihilo, mas sempre esteve condicionado a incontáveis ordens de realidade, nunca estáticas, mas dinâmicas, e que se alternam, conforme igualmente se modificam outros inumeráveis fatores que a vida continuamente proporciona.

3. A História do Direito e os vários ramos da ciência jurídica. Interdisciplinaridade. Fontes.

Onde há de se colocar a História do Direito entre os vários ramos que este último comporta? Costuma-se dizer que o historiador é reconhecido pelos juristas... como um bom historiador e, entre os colegas historiadores, como um bom jurista. Se por um lado não deixa de ser incômoda a sua insistência em retroagir ao estado temporal das questões que examina, também esta ressalta na mentalidade jurídica, tônica que identifica todos os temas que aborda. ${ }^{4} \mathrm{O}$ vastíssimo campo pelo qual atua conduz necessariamente à interdisciplinaridade, pois está ele tanto às voltas com as instituições de Direito Público, quanto de Direito Privado; aqui, o tema é de Direito Civil, ali, de Direito Penal, Processual, Administrativo... Nem vale a pena estabelecer algumas regras para esse fim: durante a Idade Média, por exemplo, uma das principais características do período é justamente a ausência de regras e de parâmetros estanques que possam melhor orientar o pesquisador.

E a tarefa torna-se ainda mais complexa quando o leque se amplia até a Filosofia do Direito ou ao Direito Constitucional, presentes no estudo da evolução do pensamento jurídico e das idéias políticas. Para uma possível compreensão do conteúdo da História do Direito, muito ajuda, por certo, a classificação das fontes nas quais esta se escora, sejam elas jurídicas ou não; entre as primeiras, principalmente as leis e os costumes, sem que se desprezem as secundárias, fartas em número e que se acham dispersas nos tratados, contratos, termos, documentos, tabuletas, alvarás, testamentos, etc. As segundas compreendem acervo ainda mais extenso: obras filosóficas, históricas, científicas, literárias, artísticas; a contribuição do folclore, das lendas e mitos populares, dos hábitos culturais e religiosos, a maneira como se vestiam as pessoas, alimentavam-se, qual o tratamento que se davam nas relações do dia a dia, os estamentos sociais em que se dividiam. Tantas

4. Hans Thieme, Ideensgeschichte und Rechtsgeschichte, p. 288 apud José Antonio Escudero, Curso de Historia del Derecho, Madri, 1995, p. 33. 
marcas e sinais, imagens vívidas de um povo sobre o qual se pretende esmiuçar as origens, tendências, inclinações, o seu grau de civilização, enfim.

A amplitude do domínio que a História do Direito abarca, constitui o selo mais significativo da sua importância e valor entre as ciências jurídicas. Não estorvam lindes espaciais ou temporais, nem balizas geográficas ou cronológicas: estas poderão ser adotadas eventualmente, quando necessárias ao melhor entendimento deste ou daquele objeto, ou para que o leitor não se perca em anacronismos. Mas a investigação é tanto sincrônica, quanto diacrônica de modo a permitir, assim, a percepção de um sistema jurídico como um todo, bem como a valoração das gradações cambiantes que nele ocorreram. De há muito deixou de ser meramente descritiva, para fornecer a reconstrução viva dos fatos, colocando-os à luz de "processos orgânicos e evolutivos"; trata-se de conhecer "o ambiente físico, os fatores étnicos e o meio social em que as instituições jurídicas nascem e se desenvolvem; $e$ de observar a origem e transformação dessas instituições, relacionando-as como o condicionalismo social e natural de que são produto" 5

Para que se tenha uma breve idéia de como este lavor empolga, basta exemplificar que do exame de tais impulsos concluir-se-á que nem sempre o Direito positivo vigente em determinado período histórico, em dada região, vinha conforme a consciência jurídica do povo que a habitava; que nem sempre as leis ditadas com soberba pelas autoridades governantes recebiam respaldo entre a população encarregada de as suportar...

4. A História do Direito, disciplina obrigatória integrante dos cursos jurídicos.

A História do Direito, embora presente desde épocas remotas que se perdem na origem das civilizações, teve o seu estudo institucionalizado de dois séculos para cá, incorporando-se definitivamente ao elenco das ciências jurídicas, de modo a constituir disciplina obrigatória para a formação de todo aquele que procura um completo conhecimento do saber, no campo do Direito.

Para comprovação desta assertiva, impõe-se, então, o retorno ao século XVIII e ao regime que vigia em Portugal e, por conseqüência, no Brasil, antes da Independência.

5. Waldemar Martins Ferreira, História do Direito Brasileiro, Rio-São Paulo, Livraria Freitas Barros, 1951, pp. 17-18. 
Passava-se por crítico período, pois o guante colocado sobre as idéias, e a censura, distintivos do absolutismo, forçavam o imobilismo da sociedade e de suas eventuais vocações. E o Direito no qual aquela se arrimava seguia por igual destino, conformando-se os juristas em repetir "o longo préstito de autores", abusando da fastidiosa enfiada de remissões, tão bem exemplificadas nas obras dos tratadistas da época. O marasmo científico e intelectual traduzia o ferrolho aos estímulos e a estagnação dos espíritos, enquanto as regras universitárias, alheias ao que sucedia no continente, advertiam aos estudantes em cânones e leis que eles se detivessem, por cinco cursos inteiros, na leitura das Institutas, do Digesto, do Decreto de Graciano, das Clementinas, do Sexto... e nada mais. (Estatutos da Universidade de Coimbra de 1559, capítulos 99, 100 e 101). ${ }^{6}$

Esta incompreensível imutabilidade sacudiu-a o terremoto de Lisboa, levantando dos escombros da tragédia as idéias que o Iluminismo carreava. E a Lei da Boa-Razão, de 1769, ainda que editada sob o crivo do Absolutismo, veio promover sensíveis modificações no quadro político e administrativo da nação lusa, as quais teriam que influir, por sua vez, na estrutura do Direito até então utilizado.

Já alguns anos antes, porém, discutia-se a necessidade de acompanhar o movimento de renovação cultural que corria pela Europa, estendendo-se este debate até a área do ensino do Direito; nas cartas dedicadas a este tema, Luís Antônio Verney advertia: "Quem sabe somente quatro apostilas, ainda que as tenha presente na memória, eu não o distingo do papagaio que repete aquilo que ouviu muitas vezes. Isto não é ser jurista, nem para lá vai" (Verdadeiro Método de Estudar, v. IV carta 13a, I, c, 3). E continuava: se um jurista desconhece a História Civil, principalmente a Romana e um teólogo ignora a História da Igreja, "sem mais outro exame assente que nem Leis, nem Teologia sabe; porque a História é uma parte principal destas duas faculdades, sem a qual não é possivel que um homem as entenda" (I, d, 1). ${ }^{7}$

A apreciação do exímio educador não se limitou à crítica sobre a maneira ultrapassada pela qual era ministrado o curso jurídico na Universidade de Coimbra; aprofundou-se o autor na descrição detalhada dos "métodos recomendados

6. Estatutos da Universidade de Coimbra, 1559, Padre Serafim Leite, 1963, por ordem da Universidade, pp. 278 e ss. Estes estatutos seriam alterados, em parte, antes de 1772, mas não o sistema de ensino.

7. Luis Antônio Verney, Verdadeiro Método de Estudar, Lisboa, Sá da Costa, 1952, v. IV, pp. 117 e 119. 
para as diferentes disciplinas jurídicas, segundo o critério exposto pelo notável iluminista italiano, Luiz Antônio Muratori, de quem se considerava discípulo" 8 A longa exposição que faz sobre a matéria compõe um dos capítulos de seu trabalho (II, b, 1, 2, sq.), partindo do princípio de que o jurisconsulto tem manifesta necessidade do estudo da História "visto ser ela a que mostra por que fim e em que circunstâncias e tempo foram feitas as ditas leis" já que "muitas delas parecem contrárias as outras" (II, a).

Não há propósito em demorar na exposição sistemática dos estudos sugeridos, bastando acrescentar que se acolheram quando da divulgação dos novos estatutos da Universidade, no ano de 1772; ao tratar das disciplinas que deveriam ser ensinadas no curso de Direito Civil, as normas ali contidas dispuseram que "nenhum Direito pode ser entendido sem um claro conhecimento prévio, assim do Direito Natural, Público e Universal e das Gentes; como da História Civil das Nações e das leis para elas estabelecidas, conforme as diferentes épocas dos tempos e as diversas conjunturas que nelas ocorreram; por serem estas prenoções indispensáveis para a verdadeira inteligência de todas as leis e do genuíno sentido delas. Mando que no sobredito Curso Jurídico haja lições públicas: $I^{o}$ : de Direito Natural, Público Universal e das Gentes; II : de História Civil do Povo e do Direito Romano; III ${ }^{o}$ : da História Civil de Portugal e das Leis Portuguesas" (Estatutos da Universidade de Coimbra, Liv. II, Tít. II, cap. III, item 9). O programa das lições de História do Direito Civil, Romano e Português, prossegue no capítulo VI do mesmo título e Livro dos estatutos, ali se especificando, quanto à última seção, que seriam estudadas as leis, usos e costumes legítimos da nação portuguesa, passando, depois, à História da Jurisprudência Teorética, ou Ciência das Leis em Portugal, e à História da Jurisprudência Prática, ou do exercício das Leis (Tít. III, cap. IX, 1). ${ }^{10}$

O professor designado para reger a cadeira seria obrigado a formar um "Compêndio Elementar de História do Direito" (Tít. III, cap. IX, 14), "' tarefa da qual se incumbiu Pascoal José de Melo Freire dos Reis, dando a conhecer a sua Historiae iuris civilis Lusitani liber singularis, a qual seria reconhecida oficialmente para o

8. Moacyr Lobo da Costa, A Revogação da Sentença, São Paulo, EDUSP/Ícone, 1995, p. 186.

9. Luís Antônio Verney, ob. cit., pp. 159 e ss.

10. Estatutos da Universidade de Coimbra, 1772, Coimbra, 1972, por ordem da Universidade, pp. 284 e 357.

11. Estatutos da Universidade de Coimbra, 1772, cit., p. 364. 
estudo da disciplina. Desde 1774, todavia, esta vinha sendo ministrada pelo insigne jurista, sendo certo que, a partir dessa data, nunca mais deixou de figurar no currículo do curso jurídico da Faculdade de Direito da Universidade de Coimbra.

A par da contribuição bibliográfica dos professores que se the seguiram, Francisco Coelho de Sousa e São Paio (1789) e Ricardo Raimundo Nogueira (1795), a historiografia jurídica conheceu expressivo influxo, mormente após a criação da Academia Real das Ciências de Lisboa: Antônio Caetano do Amaral, José Anastácio de Figueiredo, João Pedro Ribeiro, José Veríssimo Alves da Silva são nomes que ressaltam entre a produção científica do período a qual continuaria ainda com maior significado durante o curso do século XIX, aí despontando a contribuição de Manoel Antônio Coelho da Rocha, do vulto superior que foi Alexandre Herculano, do dedicado empenho de Henrique da Gama Barros. Na seqüência, já para os nossos dias, entre outros, José Ferreira Marnoco e Souza, Manoel Paulo Merea, Luís Cabral de Moncada, Guilherme Braga da Cruz, Marcello Caetano, Mário Júlio de Almeida Costa e Nuno Espinosa Gomes da Silva.

Hoje, a História do Direito permanece como disciplina fundamental do currículo de todas as Faculdades de Direito de Portugal: está no primeiro ano da tradicional Faculdade de Direito da Universidade de Lisboa. A presença ocorre, da mesma forma, no curso de pós-graduação, compondo o conjunto das ciências legais históricas. Ainda na graduação, vem contemplada no curso de Direito da Universidade Autônoma de Lisboa "Luís de Camões" ( $1^{\circ}$ ano, História das Instituições); da Faculdade de Direito da Universidade Católica Portuguesa $\left(1^{\circ}\right.$ ano, História do Direito Português); no Departamento de Direito da Universidade Internacional, Lisboa ( $1^{\circ}$ ano, História do Direito); na Faculdade de Direito da Universidade Católica Portuguesa, Porto $\left(1^{\circ}\right.$ ano, História do Direito); no Departamento de Direito da Universidade Portocalense, Porto $\left(1^{\circ}\right.$ ano, História das Instituições), etc.

5. O ensino da História do Direito no Brasil.

No Brasil, o estudo de História do Direito, embora não contasse com cadeira própria, quando da instituição dos cursos jurídicos, sempre esteve presente na preocupação dos educadores e no magistério desenvolvido nas Faculdades de Direito de São Paulo e do Recife. 
Assim é que a Carta de Lei de 11 de agosto de 1827, ao criar os cursos jurídicos, dispôs que seriam provisoriamente regidos, no que fossem aplicáveis e enquanto a congregação de lentes não-elaborasse o seu regulamento, pelos estatutos de autoria de Luiz José de Carvalho e Mello, Visconde da Cachoeira; na exposição detalhada que estes fazem das disciplinas do currículo, incluiu-se a História do Direito, de tal forma que o professor remontasse "às origens da monarquia portuguesa, referindo as diversas épocas, os diversos códigos e compilações e tudo mais que fosse necessário para que os estudantes conhecessem, a fundo, a marcha que tem seguido a ciência do Direito Pátrio até o presente. 12

Mais tarde, a reforma estabelecida pelo Decreto n. 1.134 , de 30 de março de 1853, referendada no ano seguinte, pelo Decreto n. 1.386, de 28 de abril, inseria, no terceiro ano, a cadeira de Direito Civil Pátrio com análise e comparação do Direito Romano, demonstrando a importância dada às raízes históricas.

Entre a literatura jurídica correspondente que se seguiu, Sacramento Blake anota em sua compilação o "Tratado sobre as fontes do Direito Positivo para servir de introdução a um curso de Direito Pátrio" de autoria do conselheiro João Crispiniano Soares, catedrático de Direito Romano a partir de 1854, trabalho escrito em colaboração com o conselheiro Joaquim Ignácio Ramalho, outro mestre da Casa. $^{13}$

Aliás, a busca às fontes dos institutos a estudar constituía método comum entre os juristas do período, bastando remontar às obras então publicadas entre as quais, à título de exemplo, cite-se o clássico "Da posse e das ações possessórias segundo o Direito Pátrio comparado com o Direito Romano e o Canônico" do Conselheiro Antônio Joaquim Ribas, catedrático de Direito Romano na década 1860-70. Na verdade, a utilização do método histórico-dogmático prossegue, "assinalando o valor da história para explicar o espírito da legislação", interpretando-a como fato da vida e da sociedade numa extensa sucessão de manifestações do pensamento humano. ${ }^{14}$

12. Alberto Venâncio Filho, Das Arcadas ao Bacharelismo, São Paulo, Ed. Perspectiva, 1982, p. 32.

13. Augusto Victorino Alves Sacramento Blake, Dicionário Bibliográfico Brasileiro, Rio de Janeiro, $1883,3^{\circ}$ v., p. 396 e $4^{\circ}$ v., p. 152 , referindo-se aos mestres citados; J.A.Almeida Nogueira, Academia de São Paulo - Tradições e Reminiscências, São Paulo, 1900, sexta série, 6º v., p. 73.

14. Alfredo Buzaid, prefácio à obra Origem e Introdução da Apelação no Direito Lusitano, de Luiz Carlos de Azevedo, São Paulo, FIEO, 1976. 
Marco ainda mais expressivo da época do Império, todavia, são os pareceres de Rui Barbosa sobre a reforma do ensino secundário e superior: na parte em que se dedica ao ensino jurídico, sugere ele a adoção da cadeira de "História do Direito Nacional, matéria de primeira ordem, que contém, por assim dizer, a história das origens, dos monumentos e da evolução das instituições do país. É curso que encontramos estabelecido em quase todas as Faculdades de Direito organizadas. 15

Finalmente, às vésperas do novo regime, é aprovada a Reforma Franco de Sá (1885), a qual dividiu o curso de direito em dois ramos, criando também, várias novas cadeiras: entre elas, a de História do Direito.

Proclamada a República, por iniciativa de Benjamin Constant, titular da Pasta de Instrução Pública, é promulgado o Decreto n. 1.232-H, de 2 de janeiro de 1891: separam-se os cursos de Direito em ciências jurídicas, ciências sociais e notariado: no primeiro, aparece a cadeira de Filosofia e História do Direito; e, também, a de História do Direito Nacional. No segundo, repete-se apenas a de Filosofia e História do Direito. Para esta última, em São Paulo, incumbiu-se da regência o professor Pedro Lessa, enquanto o professor Aureliano de Souza e Oliveira Coutinho foi nomeado catedrático de História do Direito Nacional, por Decreto de 21 de março de 1891. No Recife, a partir do mesmo ano, ficou responsável pela História do Direito Nacional o professor Isidoro Martins Júnior, autor do conhecido compêndio que leva o mesmo nome da disciplina e que, por sua importância, mereceu publicação oficial em 1979.

Mas, como lembra o Professor Waldemar Ferreira no primeiro capítulo da sua "História do Direito Brasileiro" verificou-se que não se ajustava bem o ensino concomitante ou mesmo sucessivo da Filosofia e História do Direito na mesma cadeira, por prejudicar "o desenvolvimento expositivo de uma ou outra matéria." 16

Quando da reorganização dos currículos nas Faculdades de Direito, ocorrida em 1895 (Decreto n. 314) fixa-se a disciplina denominada História do Direito especialmente do Direito Nacional no $5^{\circ}$ ano $\left(3^{\mathrm{a}}\right.$ cadeira), passando a ministrá-la, em São Paulo, o citado professor Aureliano Coutinho. A Revista da

15. Rui Barbosa, Reforma do Ensino Secundário e Superior, in Obras Completas de Rui Barbosa, v. IX, t. I, p. 108, Rio de Janeiro, 1942.

16. Waldemar Martins Ferreira, ob. cit., pp. 12-14. 
Faculdade de Direito de São Paulo, do ano de 1896 (v. IV), traz o discurso inaugural por ele proferido, no qual o ilustre mestre ressalta o valor e o significado da História do Direito, quando nos désvenda a ação benéfica e incessante desse poderoso fator de civilização, que acompanha o homem na sua marcha progressiva para o ideal de perfeição. ${ }^{17}$

Sobrava-lhe o intuito de elaborar compêndio a respeito da matéria, tanto que assim o declara na mesma oração, ao acentuar que à cadeira da História do Direito Nacional, da qual fora o primeiro catedrático, adicionava-se o ensino da História do Direito, antes anexo à Filosofia do Direito. De tal sorte, a duplicação da responsabilidade animava-o ao projeto, inviabilizado por súbito falecimento; substituiu-o o professor João Pedro da Veiga Filho, nomeado por Decreto de 12 de maio de 1897.

Assim, de 1891 até 1901, quando sobrevém nova reforma no ensino do Direito (Decreto n. 3.903, de 12 de janeiro de 1901) suprimindo a cadeira, foi ela ensinada, nesta Faculdade, por dois notáveis educadores e juristas.

De seu retorno por mais de uma vez se cogitou: Aurelino Leal anota em livro publicado em 1907, sobre A Reforma do Ensino do Direito no Brasil, que existia projeto na Câmara visando a sua inclusão no programa; no ensejo, o autor oferecia um substitutivo, insistindo pelo Direito Romano, no $1^{\circ}$ ano, e pela História do Direito Nacional, no $2^{\circ}$; e dizia que "eliminar dos programas das Faculdades de Direito os estudos históricos é desconhecer a atual compreensão pedagógica que manda remontar às origens, para que a assimilação seja mais completa e mais sólida, pois, a cultura. ${ }^{18}$

Décadas mais tarde, o Primeiro Seminário de Ensino Jurídico, realizado em 1967, sob o patrocínio do Instituto dos Advogados Brasileiros, ao tratar do currículo mínimo do curso de Direito, ampliava aquele estabelecido em 1962, pelo Conselho Federal de Educação (Parecer n. 215, Documenta n. 10) para incluir, entre outras disciplinas, a História do Direito.

Aliás, esta já vinha sendo lecionada em inúmeras Faculdades de Direito do país: a História do Direito, especialmente do Direito Brasileiro, do professor Haroldo Valladão, que contém, no apêndice, o programa respectivo, adotado no Centro de Ciências Sociais da Pontifícia Universidade Católica e na

17. Revista da Faculdade de Direito de São Paulo, v. IV, 1896.

18. Alberto Venâncio Filho, ob. cit., p. 240. 
Universidade Federal, ambas do Rio de Janeiro (1962-72) é o melhor comprovante de sua inclusão e difusão pelos cursos jurídicos brasileiros. ${ }^{19}$

Na Faculdade de Direito da Universidade de São Paulo, depois de reaberto o curso de doutorado, o professor Waldemar Ferreira desenvolveu, em curso regular, as suas preleções sobre a História do Direito Nacional, as quais iriam compor, a seguir, a sua clássica obra, História do Direito Brasileiro, publicada a partir de 1951.

Anos mais tarde, extinto o curso de doutorado e criado o de pósgraduação, nos níveis de mestrado e doutorado, os estudos históricos continuaram a compor o rol das disciplinas ofertadas aos interessados, distribuídas na História do Direito e na História do Processo Romano, Canônico e Lusitano, sob a regência, respectivamente, dos professores Alexandre Augusto de Castro Corrêa e Moacyr Lobo da Costa.

No curso de graduação, quando das modificações introduzidas na estrutura curricular, criaram-se, em 1990, as disciplinas História do Direito e do Pensamento Jurídico I e II (DCV 328, com três créditos e DCV 329, com dois créditos) a serem ministradas, respectivamente, no $5^{\circ}$ e $6^{\circ}$ semestres (sessão de 30 de maio de 1989, da Comissão de Graduação, presidida pelo professor Antonio Junqueira de Azevedo e ofício datado de 4 de julho desse mesmo ano, endereçado pelo então Diretor da Faculdade, professor Dalmo de Abreu Dallari, à Secretaria da Universidade de São Paulo of. ATC/155/FD/04/07/1989).

Foram designados como responsáveis pela regência das disciplinas os professores Antonio Junqueira de Azevedo e Cláudio De Cicco, passando o programa a fazer parte da referida estrutura curricular; e na seqüência, tendo em vista nova resolução da Comissão de Graduação, para atender ao melhor desenvolvimento do curso, as disciplinas mencionadas passaram a ser ministradas no $3^{\circ}$ e $4^{\circ}$ semestres (segundo ano do ciclo institucional) com igual carga horária e atribuição de créditos, delas se incumbindo os professores Luiz Carlos de Azevedo, Ignácio Maria Poveda Velasco e José Reinaldo de Lima Lopes. Hoje, para o Departamento de Direito Civil, a disciplina denomina-se "História do Direito"

O conteúdo do programa segue o mesmo teor, a par das naturais alterações introduzidas pelos atuais mestres das disciplinas, os quais têm procurado

19. Haroldo Valladão, História do Direito, especialmente do Direito Brasileiro, Rio de Janeiro, 1972. 
enfatizar, além do embasamento histórico-dogmático que aquele possui, um sentido particularmente humanístico nas preleções, como elemento imprescindível de formação do estudante de Direito, seguindo, aliás, neste passo, o mesmo critério adotado pelos professores que os antecederam; além disto, tem sido desenvolvido, de forma aprofundada, o ensino de temas de expressiva importância na formação do aluno, como faz exemplo o estudo do Direito Comum e da sua introdução no Direito Lusitano ao tempo da criação das Universidades Medievais, ressaltando a influência que aquele teve na elaboração das Ordenações do Reino; procura-se, assim, valorizar a nossa tradição jurídica e o embasamento romano-canônico no qual esta se assenta para que os estudantes possam se familiarizar com os fundamentos históricos do Direito que irão futuramente exercitar na vida profissional; não se descura, finalmente, do ideal ético e moral que há de prevalecer na consciência daquele que se dedica a todos os ramos profissionais que o Direito proporciona. E há uma atenção especial para a História do Direito Brasileiro, desenvolvida de modo mais específico na última parte do programa.

Vale acrescentar que a receptividade destes estudos tem sido extremamente significativa, circunstância que se denota tanto nas aulas teóricas quanto no desenvolvimento de seminários e atividades extracurriculares.

Acrescente-se, ainda, no âmbito nacional, que a permanência da disciplina História do Direito no currículo que lhe corresponde tem sido constante preocupação daqueles incumbidos de diagnosticar e oferecer perspectivas c propostas para o ensino jurídico: a Comissão da Ordem dos Advogados, em 1991, ao traçar diretrizes a esse respeito, dispôs que o currículo deve ter composição tridimensional integrada, interligando disciplinas de formação geral, disciplinas profissionalizantes e atividades práticas, sendo que as primeiras têm por finalidade desenvolver a formação fundamental do aluno, capacitando-o ao raciocínio jurídico, à interdisciplinaridade, à reflexão crítica, às transformações sociais e jurídicas, incluindo-se aí, entre outras, a Sociologia, Filosofia, História do Direito, Hermenêutica, Ética e as teorias gerais abrangentes dos vários ramos do Direito Privado e Público.

Dois anos mais tarde, participantes do Seminário Nacional dos Cursos Jurídicos, realizado em Brasília, no tema relativo à elevação da qualidade e avaliação, concluíram que "era necessário proporcionar ao acadêmico embasamento humanístico, com ênfase nas disciplinas como Filosofia Geral, Filosofia Jurídica, Sociologia Jurídica e outras matérias fundamentais $e$ 
interdisciplinares, a exemplo da Sociologia Geral, Teoria Geral do Direito, Hermenêutica, Economia, Metodologia Científica, História do Direito, Português e Linguagem Jurídica, Fundamentos da Ética Geral e Profissional"

Por último, a Portaria n. 1.886, de 30 de dezembro de 1994, ao fixar as diretrizes curriculares e o conteúdo mínimo do curso jurídico, embora nãomencione expressamente a disciplina História do Direito, a esta acaba se reportando, de modo genérico, quando dispõe no parágrafo único do art. $6^{\circ}$ que as demais matérias e novos direitos (além daqueles especificados nos itens I e II) serão incluídos nas disciplinas em que se desdobrar o currículo pleno de cada curso, de acordo com as suas peculiaridades e com observância da interdisciplinaridade.

Como já se fez menção, nas Faculdades de Direito brasileiras, o ensino de História do Direito não tem sido descurado, fazendo parte do currículo de inúmeros estabelecimentos de ensino superior, seja como disciplina autônoma, seja como integrante das matérias básicas, lecionadas nos primeiros anos do curso.

6. O ensino da História do Direito no exterior.

No exterior, em especial naqueles países que adotam o denominado sistema continental (família romano-germânica) e que encontra suas raízes no Direito Comum, romano-canônico, a disciplina é lecionada obrigatoriamente, na grande maioria das Faculdades de Direito.

Na Áustria, suas Universidades (Viena, Graz, Innsbruck, Salzburg, Linz) a incluem nos cursos de Direito, compondo a primeira seção, ou seja, contemplando-a como uma das matérias básicas fundamentais, ao lado da Introdução ao Direito, Direito Romano, Sociologia.

Na Bélgica, a Faculdade de Direito da Universidade Livre de Bruxelas traz no primeiro ano de graduação a História da Bélgica, a História do Direito e o Direito Romano; a Faculdade de Direito da tradicional Universidade Católica de Louvain, também oferece em seu currículo a referida disciplina.

Na França, a História do Direito ou a História das Instituições, é lecionada praticamente em todas as Faculdades de Direito, uma vez que se trata de matéria fundamental do primeiro ciclo; assim, por exemplo, na Paris II (Université Panthéon, onde funciona, igualmente, um Centro de Estudos de História do Direito), em Dijon (Université Jean Moulin), em Nancy, Bordeaux, etc. 
$\mathrm{Na}$ Alemanha, os cursos de Direito incluem, entre as matérias compulsórias, a Teoria Geral do Direito, a qual se desdobra em Filosofia do Direito, História Legal e Constitucional e História do Direito Romano.

Na Itália, o ensino da História do Direito, a qual adota várias denominações e abrangências (História do Direito Italiano, História da Codificação, História do Direito Italiano Moderno, etc.), é obrigatório em todas as Faculdades de Direito.

Na Espanha, a Faculdade de Direito da Universidade Complutense de Madri apresenta um programa detalhado da matéria que se desenvolve desde o conceito da disciplina, passando pelos direitos primitivos, pela Romanização, Direito Visigótico e Medieval, Direito dos vários reinos que irão constituir a nação espanhola, até chegar ao Direito na atualidade. Em outras universidades, é estudada com o título de História da Legislação, Estrutura e Evolução do Direito Espanhol, etc.; mas está sempre presente no currículo de todas as Faculdades de Direito.

Em outros países europeus, o estudo da História do Direito é por regra obrigatório, situando-se logo nos primeiros anos do ciclo básico: na Polônia, a Universidade de Cracóvia, em seu curso de Direito, ministra História do Direito Comparada e a História do Direito e das Doutrinas Políticas; com o nome de História Geral do Direito, está no currículo da Faculdade de Direito da Universidade de Gdansk; na Universidade de Varsóvia, com o título de História do Direito Polonês e História Geral do Estado e do Direito. A História do Estado e do Direito Búlgaro é estudada no curso respectivo da Universidade de Sofia, Bulgária; na Croácia, é estudada em Rijeka (História Geral do Estado e do Direito), Split (História Mundial e História Nacional do Direito), em Zagreb; na Universidade Carlos, da República Tcheca (História do Direito Tcheco, Eslovaco, na Europa e nos Estados Unidos da América); na Finlândia, Hungria, Suécia, Suíça, Turquia, na secular Universidade de Oxford, no Reino Unido; na Eslováquia, Lituânia, Holanda, Noruega... 20

20. Guide To Legal Studies In Europe, Bruxelas, Law Books in Europe, 1995, pp. 15, 65, 69, 83, 87, $99,101,113,117,121,135,153,167,173,182,199,211,213,229,237,255,597,599,601,637,663$, $671,689,721,725,737,751,755,759,761,774,807,819,825,891,895,903,925,965,1127$, etc. 
7. A consolidação da História do Direito como disciplina obrigatória do currículo do curso de graduação da Faculdade de Direito da Universidade de São Paulo.

Na Faculdade de Direito da Universidade de São Paulo, nestes oito anos que se escoaram, a História do Direito prossegue fazendo parte dos ciclos básico e institucional, na condição de disciplina obrigatória, sendo regularmente ministrada no curso de graduação, terceiro e quarto semestres, sem interrupção de continuidade.

Por outro lado, periodicamente, têm sido abertos concursos para a contratação de docente, na categoria de doutor, junto ao Departamento de Direito Civil, áreas de Direito Romano e de História do Direito; e concursos para a livredocência do Departamento de Direito Civil, área de História do Direito.

Em tais condições, sua posição como disciplina integrante do curso jurídico já se encontra consolidada: na verdade, desde 1772, quando da reforma dos Estatutos da Universidade de Coimbra e a conseqüente instituição das lições de História do Direito Civil, Romano e Português; desde 1827, quando da criação dos cursos jurídicos no Brasil, ao participar, naturalmente, do programa das disciplinas que compunham o currículo; de modo mais específico, desde 1891, quando da Reforma do Ensino Jurídico e a adoção da cadeira de História do Direito Nacional; a partir de 1895, com o nome de História do Direito especialmente do Direito Nacional; e, finalmente, desde 1990, quando passou a ser novamente lecionada no curso de graduação.

Não se trata de novidade, nem pode constituir surpresa, a atribuição de cadeira à referida disciplina, a menos se desconheça a realidade dos fatos secularmente apontados e a própria realidade presente; constitui a conseqüência lógica, resultante destas duas realidades incontornáveis. 
8. Conclusão.

Para concluir, vale transcrever, aqui, quanto disseram, como o professor Waldemar Ferreira, ao ressaltar a importância da História do Direito, como ciência e disciplina: "nenhum jurista pode dispensar o contingente do passado a fim de bem compreender as instituições jurídicas dos dias atuais. Ninguém é capaz de dar um passo à vanguarda, adiantando um, sem deixar o outro pé na retaguarda. Diferentemente não se realizam caminhadas" 21

Do mesmo modo a oportuna lição de Henri de Page, transcrita por John Gilissen na sua Introdução Histórica do Direito, cuja tradução portuguesa tem se revelado tão-útil aos estudantes:

"A história do direito é muitas vezes tratada com um condescendente desdém, por aqueles que entendem ocupar-se apenas do direito positivo. Os juristas que se interessam por ela, quase sempre à custa de investigações muito longas $e$ muito laboriosas, são freqüentemente acusados de pedantismo... Uma apreciação deste gênero não beneficia aqueles que a formulam. Quanto mais avançamos no direito civil, mais constatamos que a História, muito mais do que a Lógica ou a Teoria, é a única capaz de explicar o que as nossas instituições são as que e porque é que são as que existem" 22

São Paulo, dezembro de 1997.

Bibliografia.

GALLO, Alfonso Garcia. Manual de Historia del Derecho Español, Madri, 1975.

CLAVERO, Bartolomé. Institucion Historica del Derecho, Madri, Marcial Pons, 1992.

BARCHET, Bruno Aguilera. Historia y Derecho, Barcelona, 1994.

21. Waldemar Martins Ferreira, ob. cit., p. 11.

22. Henri de Page, Traité de Droit Civil Belge, Bruxelas, 1942, p. 806, apud John Gilissen, Introdução Histórica ao Direito, tradução de Antônio Manoel Hespanha e L.M. Macaísta Malheiros, Lisboa, Fundação Calouste Gulbenkian, 1979, p. 13. 
VALIENTE, Francisco Tomás y. Manual de História del Derecho Español, Madri, Tecnos, 1980.

Guia del Estudiante. Universidad Complutense, Madri, 1992.

Guide des Études de Droit. Paris, Dalloz, 1991.

CRUZ, Guilherme Braga da. História do Direito Português, Coimbra, 1995.

TUCCI, José Rogério Cruz e. e AZEVEDO, Luiz Carlos de. Lições de História do Processo Civil Romano, São Paulo, RT, 1996.

CARVAlHO, Laerte Ramos de. A Reforma Pombalina da Instrução Pública, São Paulo, EDUSP-Saraiva, 1978.

ROCHA, Monuel Antônio Coelho da. Ensaio sobre a História do Governo e Legislação de Portugal, Coimbra, Imp. Universidade de Coimbra, 1872.

CAETANO, Marcello. História do Direito Português, Lisboa, Verbo, 1981.

COSTA, Mário Júlio de Almeida. História do Direito Português, Coimbra, Almedina, 1989.

Ordine Degli Studi e Programma dei Corsi. Università degli Studi di Roma "La Sapienza". Roma, 1991-92.

RODRIGUES, Horácio Wanderley. Novo Currículo Mínimo dos Cursos Jurídicos, São Paulo, RT, 1995.

Revista da Faculdade de Direito de São Paulo. vols. II, 1894; IV, 1896; V, 1897; XX, 1912.

FERREIRA, Waldemar Martins. A Congregação da Faculdade de Direito de São Paulo na Centúria de 1827 a 1927. São Paulo, Tip. Siqueira, 1928.

VAMPRÉ, Spencer. Memórias para a Academia de São Paulo, São Paulo, Saraiva, 1924. 